\title{
O PODER DAS HISTÓRIAS DE PEQUENO E DAS PEQUENAS HISTÓRIAS: UMA RELEITURA DE O SAGRADO NA VIDA COTIDIANA, DE M. LEIRIS
}

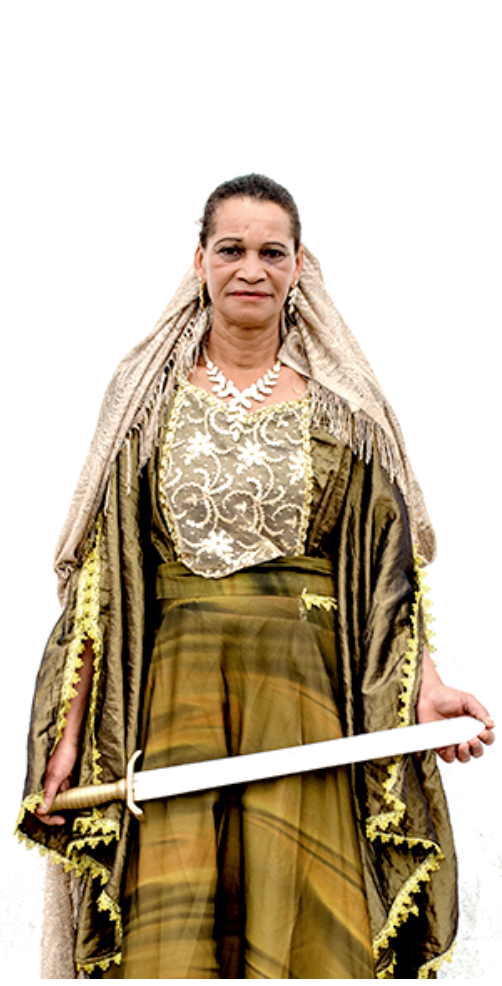

Edilson Pereira ${ }^{1}$

"A história de Judite - heroína duas e três vezes terrível, porque, primeiramente viúva, torna-se em seguida assassina, e assassina do homem com quem, no instante anterior, se deitou - não me impressionou muito quando a li pela primeira vez, em criança, no livrinho de História sagrada em que me era contada. É verdade que todo detalhe licencioso havia sido rigorosamente banido. [...] Mas Judite, que cortou a cabeça do amante com a própria espada dele, envolvendo-a a seguir com um véu ou pondo-a num saco a fim de levá-la, é a figura em torno da qual cristalizam imagens que tiveram uma influência decisiva em minha vida." (Leiris, 2003, p. 87)

1 Professor do Departamento de Antropologia e do Programa de Pós-graduação em Ciências Sociais da UERJ. Contato: edilperei@yahoo.com.br 
Judite é uma figura-chave nas memórias que Michel Leiris guarda de sua infância. A personagem do Antigo Testamento da Bíblia é evocada com bastante frequência em A Idade Viril (L'age d'homme), livro autobiográfico no qual ele apresenta - e confessa - desejos, receios e meditaçóes que vinculam o momento da escrita, quando ele então possui 34 anos de idade, com um tempo passado. A saber, aquele no qual o autor começava a ter consciência do mundo interior e exterior. ${ }^{2}$ Uma personagem secundária dentro da História Sagrada cristá ganha relevância e uma nova significaçáo a partir do olhar de um menino/homem particular. Assim como ocorre com outras figuras femininas (mitológicas, históricas ou literárias) que ele conhecera em seu tempo de formação primeira, Judite é vista sob o manto de uma complexa relação entre pureza e violência, sacrifício e erotismo, que marcam várias obras do autor e de seus colegas surrealistas.

Em O sagrado na vida cotidiana, Leiris, entáo com 36 anos, continua o exercício de revisitação da memória (como o fará em outros artigos durante esse período de intensa produção em sua carreira), ${ }^{3}$ e traz para seu tempo presente eventos vividos quando menino. Ele enumera uma série de situaçôes

2 Leiris inicia a escrita desse livro quando possui tal idade (em 1935), mas a obra será publicada quatro anos depois, em junho de 1939. A “idade viril”, segundo o autor, começaria ainda na infância, no tempo em que desperta um tipo particular de interesse sobre as coisas e pessoas ao seu redor, incluindo sempre uma fascinação por figuras femininas - sejam virgens ou prostitutas. Por conta do contexto da Guerra na Europa, o livro não recebe atenção imediata do público e da imprensa ao ser lançado. Além disso, Leiris sugeria a inserção de um texto de abertura, no qual ele relacionava a escrita autobiográfica com a prática da tauromaquia. Esse complemento foi incluído na edição de 1946 feita pela Gallimard.

3 Em 1938, ano de apresentação do artigo em questão, ele também defende seu mémoire, La langue de la société des hommes chez les Dogons de Sanga, na sessão de Sciences religieuses da École Pratique des Hautes Études, participa da inauguração do musée de l'Homme e publica os seguintes textos: La croyance aux génies zar en Éthiopie du Nord no Journal de psychologie normale et pathologique; Miroir de la tauromachie em uma coleção homônima à revista Acéphale; e, ainda, Abanico para los toros, conjunto de 31 poemas escritos no ano anterior. (Cf. Bernadac; Hollier; La Beaumelle, 2015).

Debates do NER, Porto Alegre, ano i 8, N. 3 I, P. 4I-53, JAn./Jun. 20 I 7 
que marcaram sua infância - que se revela como terreno extremamente fértil para sua escrita, tanto quanto para uma autoanálise -, e nos leva ao interior dos cômodos e espaços domésticos que ganham tons variados, luminosos ou sombrios, veneráveis ou perigosos, oscilando sempre em função do tipo de relação mantida com tais objetos, lugares e as pessoas que os ocupam e manipulam. Nesse relato, Leiris nos apresenta um sagrado "não-oficial", que está além das convençôes sociais que instituem rituais públicos (sejam eles políticos ou religiosos) que marcam uma ruptura em relação à vida comum, ordinária. Justamente aquela que o interessa e na qual cada coisa, cada espaço, cada experiência temporal vivida e recuperada pela memória ganha uma tonalidade particular.

O que Leiris reconhece como sagrado resulta, logo, de sua percepção e atenção dada às experiências cotidianas, que ganham novos significados sob o seu olhar. Ao recuperar detalhes de momentos domésticos e familiares ocorridos décadas antes, ele agrupa vários elementos que compóem as cenas de um amplo teatro de memórias. Ao adotar a estratégia de partir de um universo de referências íntimas, pessoais, para tratar de uma noção tão poderosa como a de sagrado - que mobilizou muitos autores e debates em diferentes campos do conhecimento -, Leiris assume um novo modo, muito particular, de pensar o tema. Sua ousadia conceitual, entretanto, o levava em direção a um terreno incerto. Em associação com a forma ensaística que seu texto assume, sua relativa inovação talvez seja a principal causa para ele se sentir inseguro a respeito da qualidade do texto logo após a publicação d'O Sagrado na vida cotidiana - "[o texto] me parece, com o passar de algumas semanas, a tal ponto insuficiente e tão difícil de reformular que eu não pude reprimir minha irritação" (tradução nossa). ${ }^{4}$

A relação de potencial descontrole entre o autor e sua obra se desdobra, na verdade, como um interessante reflexo do que aparece no interior mesmo desse texto. $\mathrm{Na}$ medida em se adentra no emaranhado de suas memórias,

4 No original: "Il m’a paru, avec ce recul de quelques semaines, à tel point insuffisant, et si difficile à refondre, que je n'ai pu réprimer un mouvement d'humeur." (Correspondência de 1938, apud Bernadac; Hollier; La Beaumelle, 2015, p. 182). 
entramos também num ambiente afetivo no qual um raio de luz recai sobre objetos quaisquer destacando-lhes um traço inesperado, inédito. E essa nova faceta que se destaca, como tudo aquilo que é ainda desconhecido, traz consigo uma porção de mistério, assim como tudo aquilo que nos é proibido acessar.

Esse mistério, entretanto, não se confunde com o da teologia cristá que, embora sirva de material para diferentes alegorias produzidas por Leiris, opóe-se àquilo que se reconhece como humano e mundano. Para compreender melhor o autor, talvez valha a pena seguirmos a sugestão de Giorgio Agamben (2014, p. 71), entendendo que "em sua origem, mistério não significa 'doutrina secreta e inefável', mas 'drama sacro'.” Essa outra chave de leitura do termo permitira ao filósofo italiano perceber que o antigo processo jurídico que se desenrolava diante de Pôncio Pilatos, no pretório de Jerusalém, seria um mistério - no sentido de que ele não efetivamente profere um juízo, uma sentença que defina se o réu era culpado ou inocente e como se espera de todo processo, mas sim que aquele julgamento dava corpo a um drama de ação quase teatral. Nesse simulacro de processo narrado na Bíblia, os personagens centrais e seu público, mutuamente envolvidos, decidem ao fim pela "entrega" de Jesus para sua crucifixão - o que, segundo algumas interpretações teológicas, já estava prevista mesmo antes de acontecer.

Um mistério cênico, mundano portanto, marca o sagrado de Leiris. E nele o elemento de dramatização se repete em vários momentos d'O sagrado na vida cotidiana. A sala de banho e privada do banheiro se revestem de um novo caráter na narrativa de Leiris. Eles se tornam lugares de conspiração e representação de poder dentro noites compartilhadas com seu irmão mais velho, quando inventavam mil histórias de guerra e vinganças. Naquele pequeno espaço doméstico, seu irmão mais velho assumia o papel de cúmplice e companheiro de fabulação de uma mitologia particular. Se na Roma Antiga de Pilatos existia o pretório, como lugar de fazer justiça e exercer o poder, no interior do banheiro era seu irmão que sentava "no grande trono, como um iniciado de grau superior" (ver pág. no texto traduzido) e contracenava com Leiris, mais moço, que assumia o papel de neófito, sentado sobre um reles urinol. 
A imitação e a brincadeira assumem um lugar central na produção teórica de Leiris, talvez porque ele percebesse ali, tal como descreve Walter Benjamin n’A doutrina das semelhanças [1933], que os jogos infantis são a "escola" da faculdade humana de produzir e reconhecer semelhanças. Uma faculdade humana que nos acompanharia por toda a vida, permitindo que coisas, lugares, pessoas e experiências variadas fossem associadas entre si, uma afetando o significado da outra e produzindo novas relaçóes de sentido incessantemente. Benjamin reconhece, por um lado, que "o universo do homem moderno parece contar aquelas correspondências mágicas em muito menor quantidade que o dos povos antigos ou primitivos" (1987, p. 109), mas por outro, ele enfatiza que:

"Mesmo para os homens dos nossos dias pode-se afirmar que os episódios cotidianos em que eles percebem conscientemente as semelhanças são apenas uma pequena fração dos inúmeros casos em que a semelhança os determina, sem que eles tenham disso consciência. As semelhanças percebidas conscientemente - por exemplo, nos rostos - em comparação com as incontáveis semelhanças das quais não temos consciência, ou que não sáo percebidas no todo, são como a pequena ponta do iceberg visível na superfície do mar em comparação com a poderosa massa submarina." (op. cit.)

A imagem de uma grande massa oculta, como ocorre com a maior parte de um iceberg, nos aponta para o procedimento investido por Leiris em sua recuperação e autoanálise do passado de garoto. A partir de situaçóes e imagens específicas ele passa a acessar lugares (de memória) e sentimentos profundos, que atravessam e reaparecem em diferentes épocas de sua vida. $\mathrm{Na}$ contramão do disciplinamento do pensar que a vida adulta frequentemente traz consigo, a infância se apresenta como um tempo-lugar de liberdade para reconhecer - e criar - inúmeras relaçôes entre coisas distintas, mas percebidas como semelhantes. A infância é, assim, um ambiente pelo qual não apenas se passa, mas ao qual se pode retornar - num trajeto de máodupla, no qual as experiências do presente afetam o modo de compreender o passado e vice-versa. 
Vemos isso com clareza na descrição que Leiris faz a respeito de Judite - a mesma que nos serve como legenda, neste texto, do retrato (do latim retrahere, copiar) que antecede este texto. Nela, o autor reconhece que a personagem aparentemente desinteressante de quando ele era menino, havia na verdade o marcado decisivamente. Uma imagem que pode ter ficado submersa nas profundezas da memória reaparece com toda força quando, em 1930, ele se depara com a reprodução da pintura de Lucrécia e Judite, de Lucas Cranach. Nessa obra, a figura romana e a bíblica estão ambas semidesnudas, lado a lado, cada uma com a adaga/espada (no caso da primeira, para implicar a morte a si mesma, como um sacrifício, no da segunda, Judite, a de seu amante/vítima).

A força de algo latente que foi represado no passado, como a imagem de uma mulher advinda dos tempos longínquos da História sagrada, por algum motivo, irrompe a partir do encontro com esse quadro e provoca uma nova série de associaçóes. Entretanto, assim como nas brincadeiras infantis, uma vez iniciado tal processo, ele pode se ampliar para outros campos da memória e momentos da vida. Dessa forma, também uma amiga de seus pais, tratada como "tia Lise", uma "grande e robusta brincalhona, provida de uma saúde exuberante e de uma voz esplêndida” (Leiris, 2003, p. 88) pode entrar nesse jogo. Ela costumava frequentar sua casa em noites de saraus musicais, e ao falar sobre ela, em A Idade Viril, Leiris nos conta:

"Revejo-a com seus vestidos, não muito belos mas vistosos, seus braços gordos, suas ancas bem fornidas, seus seios fartos de vaca suíça sossegada, e seus cabelos escuros, seus lábios vermelhos, sua pele fresca, seus olhos soberbos sempre excessivamente delineados, pois ela se maquiava muito mal. [...] A ouvi e vi sua foto em diversos papéis que, quase todos, têm em comum o fato de fazerem dela, desde minha infância, uma Judite.” (Leiris, 2003, p. 88-89)

O que liga tia Lise, a pintura de Cranach e a personagem narrada na História sagrada entre si? Um princípio de semelhança. Semelhança esta que, tal como compartilhada pelas coisas sagradas, não se define pelas características intrínsecas dessas pessoas e representaçôes estéticas, mas por algo que lhes é acrescentado, sobreposto. O semelhante produz o semelhante na medida em que, a priori, tanto no imaginário infantil, quanto nas operaçôes rituais 
de magia, qualquer coisa pode se assemelhar a outra. "Os jogos infantis são impregnados de comportamentos miméticos, que não se limitam de modo algum à imitação de pessoas. A criança não brinca apenas de ser comerciante ou professor, mas também moinho de vento e trem", nos dizia Benjamin naquele texto citado (1987, p. 108). E em relação aos rituais, complementarmente, basta lembrarmos da cerimônia sacrificial Haouka documentada por Jean Rouch em Les Maîtres Fous [1955] para constatar que os espíritos incorporados não representavam apenas figuras políticas ou militares, mas igualmente uma locomotiva - uma máquina-símbolo dos efeitos do poder colonial naquele contexto.

A potência que decorre do estabelecimento de associações por semelhança era bastante explorada também pelos surrealistas, muitos dos quais colegas de Leiris. Entre eles, mantinha-se a máxima de não apenas "estabelecer correspondências ao comparar os diversos elementos do universo, mas sim de inventá-las" (Moraes, 2012, p. 41). Nota-se, n’O sagrado na vida cotidiana, que as analogias que caracterizam a magia e a arte estáo para a infância assim como o sagrado oficial (da Religião, da Política e da Moral) estaria para a vida adulta. E, nesse sentido, se tomássemos a liberdade de aproximar seu texto das teorias de autores como Tylor e Frazer, veríamos que apesar de deles estarem errados em relação ao prognóstico evolucionista que faria passar da magia à religião (e depois à razão científica), talvez eles tenham acertado na associaçáo que enxergavam entre a magia e os cultos "primitivos", próximos da "infância da humanidade", por um lado, e da religião com a civilização por outro. ${ }^{5}$ Justamente a civilização que seria frontalmente criticada pelos surrealistas algumas décadas depois.

5 Além disso, para Frazer, que juntamente a Tylor foi um dos primeiros a formular as variaçóes e a progressiva evolução do pensamento humano, os princípios da magia simpática - isto é, de semelhança - eram adotados comumente pelos 'selvagens' em situações diversas, nas quais eles buscavam afetar positiva ou negativamente algo/alguém, tanto quanto evitar serem afetados: "Though these laws are certainly not formulated in so many words nor even conceive in the abstract by the savage, they are nevertheless implicitly believed by him to regulate the course of nature quite independently of human will. He thinks that if he acts in a certain way, certain consequences will inevitably follow in virtue of one or other of these laws; and if the consequences of a particular act appear 
Influenciada pela metodologia surrealista, que valorizava o subconsciente e a imaginação, a noção de sagrado segundo Leiris - um sagrado místico, lúdico e analógico - opera no sentido de tornar densas e mais complexas as coisas supostamente simples e sem importância da vida. Uma vida que se torna incontrolável e, por isso mesmo, ambígua e frequentemente perigosa. Sua análise, nesse sentido, vai ao encontro da recomendação que abre um conto de Virgínia Woolf. "Ninguém deveria deixar espelhos pendurados em casa, assim como não se devem deixar abertos talóes de cheques ou cartas que confessem algum crime horroroso". Nessa história, é através de um espelho que se vê o mundo interior de uma casa e de seu jardim ganhar vida - num enredo em que móveis, plantas e artefatos antes inanimados tornam-se todos agentes, interagindo num espaço "vazio" de gente. ${ }^{6}$

A mesma coisa ocorre com os personagens históricos, mitológicos e imaginários descritos por Leiris - seja ao recuperar a experiência de suas brincadeiras infantis ou no momento de transformá-las em escrita, como adulto. Tais figuras ganham novas cores e sentidos. Judite, entre tantas outras mulheres que mobilizaram o autor, é uma e várias ao mesmo tempo. Admiráveis, ameaçadoras e contendo sempre uma porção ainda a se desvelar. Em cada leitura da História sagrada citada pelo autor n'O sagrado na vida cotidiana e em outros escritos ele refaz a trajetória dos personagens com os quais se depara. E, nesse processo, reconstitui suas tramas em outras ordens, algumas inéditas e, por isso mesmo, potencialmente blasfemas, profanadoras de uma ordem que caracteriza o "sagrado oficial".

Acontece, entretanto, que as montagens e reenquadramentos dos personagens dramáticos e sagrados ocorre, na verdade, desde o primeiro momento de seu surgimento - como partes de um texto. A despeito da impressão que a teologia provoca sobre suas macro-narrativas, de fato, nem mesmo

to him likely to prove disagreeable or dangerous, he is naturally careful not to act in that way lest he should incur them." (Frazer, 1978, p. 25).

6 Cf. A dama no espelho: reflexo e reflexão. In: WOOLF, V. Contos completos. São Paulo: Cosac Naify, 2005.

Debates do NER, Porto Alegre, ano i 8, N. 3 I, P. 4I-53, JAn./Jun. 20 I 7 
as escrituras tomadas como legítimas - em contraste com as "apócrifas" possuem uma unicidade que permita inferir que aquela história possuiria uma única e verdadeira versão. Falando em particular do contexto cristão, Agamben enfatiza que o caráter de ambiguidade - marca central da noção de sagrado apresentada por Leiris, aliás - é uma qualidade indissociável do acesso às Escrituras:

"A ambiguidade inerente a toda interpretação dos textos sacros aparece, aqui, plenamente evidenciada. Os Evangelhos devem ser considerados como documentos históricos ou neles está em jogo, acima de tudo, um problema genuinamente teológico? Um observador pagão, Porfírio, já havia ponderado que 'os evangelistas são inventores (historas, 'testemunhas') dos eventos que concernem a Jesus. Com efeito, cada um deles escreve discordando e não concordando com os outros, sobretudo em relação à narrativa da paixão." (Agamben, 2014, p. 53)

A ambiguidade, longe de ser um problema ou uma falha, apresenta-se como qualidade fundamental para a abertura às contínuas apropriaçóes e ressignificaçóes feitas dessas mesmas histórias e personagens sagrados.

Nessa exata medida, o texto de Leiris nos dá acesso a temporalidades e eventos diversos, mas que se conectam e iluminam mutuamente. Através dele acessamos o momento de sua escrita e retornamos ao passado de sua infância. Mas, com ele, podemos também nos direcionar ao tempo presente. De minha parte, incluo o autor como um dos guias intelectuais em minha análise de práticas de representação e imitação tal como aquela da fotografia abre este texto. $\mathrm{O}$ registro, feito por mim durante a celebração da Semana Santa de 2015 em Ouro Preto (MG), nos traz à presença de uma moradora local que, assim como uma centena de outras pessoas durante essa época, veste-se como personagem bíblico para participar das procissões que atravessam o centro da cidade. Nesses cortejos, um grupo de figuras bíblicas, organizadas sequencialmente em fila, desde as primeiras do Antigo Testamento até as últimas do Novo, permitiria recompor no interior mineiro aquilo que se compreende como sendo a "História da Salvação" - que 
incluem as figuras de Moisés e Rebeca, que tanto fascinavam Leiris pela sonoridade se seus nomes. ${ }^{7}$

$\mathrm{O}$ interessante no caso ouro-pretano é que o mesmo ato que visa reconstituir as personagens da tradição cristá, reforçando a narrativa a respeito da morte e ressurreição de Jesus, permite, inevitavelmente, que se estabeleçam novas relaçóes, aproximaçóes e associaçóes tanto dos personagens sagrados entre si, quanto deles em relação aos seus intérpretes. Estudantes, donas de casa, funcionários públicos, comerciantes, pedreiros etc. assumem, durante o contexto da festa, o papel de pessoas (reais ou ficcionais, pouco importa) que viveram há milênios, muitas delas "no tempo de Cristo", como me diziam. E, nessa dinâmica, cada um(a) trazia consigo uma série de experiências, vivências e valores que afetam a imagem do personagem em questão. Judite e tantos outras figuras bíblicas são corporificadas por pessoas que, em meio a um processo de preparaçóes para "montar" os personagens - sobretudo seu figurino - podem, como dizia Benjamin, deparar-se inesperadamente com algo que estava submerso, podem reconhecer naquela persona uma semelhança inesperada com algo percebido em si mesmo, em sua própria história. Assim, a macro-narrativa que mobiliza os cristãos, no geral, ganha ali outros contornos na medida em que pode mobilizar, evocar ou mesmo transformar dramas particulares. Tenho refletido sobre esse tema, incluindo a festa ouro-pretana e seus personagens e performances, ao longo dos últimos anos (Pereira, 2014; 2015; 2016).

Além disso, quando observados mais de perto os artefatos e adereços que compóem as figuras que vão sair em procissão, nota-se que eles realizam trânsitos diversos, que os colocam em situaçóes ambivalentes, frequentemente fazendo-os alternar entre o universo doméstico, pessoal, e o da

7 Em relação à senhora retratada por mim, cabe ressaltar que naquela ocasião ela representava, na verdade, Herodíades, outra personagem bíblica que, segundo a tradição cristã, foi responsável pela morte de João Batista, cumprindo o pedido de Salomé feito ao rei Herodes. A troca das figuras (Judite x Herodíades) tem, aqui, o intuito de oferecer aos leitores um exemplo prático de quanta semelhança podemos encontrar em coisas, pessoas e personagens distintas, traçando por nossa conta novas associaçóes.

Debates do NER, Porto Alegre, ano i 8, N. 3I, P. 4I-53, JAN./Jun. 20 I 7 
igreja e do ritual público. O vestido de uma mulher, que lhe serviu para representar a personagem da Verônica se transforma, anos depois, na roupa que vai cobrir uma imagem de madeira, reconhecida então como Maria Madalena, posta sobre o altar de uma igreja. O lenço que é utilizado para distinguir a efígie de Nossa Senhora das Dores de todas as outras Nossa Senhoras, carregado em uma de suas mãos para enxugar as lágrimas que cobrem seu rosto, fica ao longo do ano guardado dentro da casa de uma senhora (de nome Maria) responsável pelas roupas da santa - lado a lado com as suas próprias roupas. A imagem barroca do Cristo que protagoniza boa parte da festa e atua, de cima do andor, em conjunto com as figuras interpretadas por pessoas, possui um perfume que só é utilizado em dia de festa - perfume esse que, no passado, pertencia ao seu antigo zelador (que passou a compartilhar com o "santo" o seu cheiro). Os reenquadramentos desses e de outros objetos nos mostram que mesmo no universo de uma festa como a da Semana Santa - que focaliza o principal momento do calendário ritual católico dentro de um ano litúrgico - o sagrado "cotidiano" continua a operar, entrecruzando-se com o oficial continuamente.

Nesse contexto, há ainda um elemento-chave a ser mencionado. Tratase dos critérios utilizados para selecionar as pessoas que representam, ano após ano, os personagens bíblicos mencionados. Como a participação desses moradores na festa não se enquadra num conjunto de cenas com diálogos e de açôes demarcadas num palco, mas sim numa sucessão linear dos personagens (em silêncio) na procissão, não se buscam atores para os papéis, mas voluntários que sejam "comprometidos" com a Semana Santa. Junte-se a isso, e talvez ainda mais importante, que a atribuição dos personagens para este ou aquele morador é definida por algumas senhoras que, há décadas, sabem identificar quem é que encarnaria melhor dado personagem. Para tanto, elas se baseiam na aparência física de cada candidato(a) a figura bíblica e na imagem (abduzida) das personagens das Escrituras. Ou seja, para cada "tipo de figura" deve corresponder um "tipo de pessoa", alguém que se pareça com - e náo apenas represente - a persona em questáo. Assim, seus corpos e rostos convertem-se nos médiuns que dão a ver, nas ruas de Ouro Preto, as personagens da Bíblia durante a festa. 
Nesse procedimento de escolha, fica evidente a ativação de um princípio associado ao domínio da magia, conforme Frazer estipulara a respeito de suas formas principais de ação, organizadas em duas leis principais: uma delas baseada no princípio da similaridade (isto é, de imitação) e outra no de contiguidade. Na releitura que Michael Taussig (1993, p. 36) faz dessa passagem de $\mathrm{O}$ Ramo de Ouro, ele a aproxima d'A doutrina das semelhanças, de Benjamin, e afirma que devemos compreender a "mimesis as the art of becoming something else, of becoming Other". Lidamos assim com uma arte de criar semelhanças - e de, no mesmo ato, reconhecê-las - que se baseia em um princípio mágico. Uma arte que é colocada em prática em função de uma grande conjuntura festiva que marca a vida social em Ouro Preto e de várias cidades históricas de Minas.

Frente à grande História sagrada, diversas outras pequenas histórias são criadas, refeitas e transformadas. Às vezes em confluência com a primeira, às vezes em sentido claramente contrário e transgressor - mas, em ambos os casos, mantendo relações de mútuo reforço. São histórias de dramas pessoais que o investimento etnográfico permite acessar e entrever de modo a fazer "explodir o continuum da História", para fazer valer a expressão de Benjamin (1987, p. 230). Ao atentar ao que há de marginal ou aparentemente pequeno dentro de um grande ritual, de um sagrado oficial, podem-se observar histórias outras, que provavelmente seriam apagadas ou esquecidas. A dessacralizaçáo da História proposta por Benjamin nos reaproxima, assim, da força dos pequenos detalhes, das minúcias que fundamentam o modo como Leiris identificava o sagrado no cotidiano.

\section{REFERENCIAS}

AGAMBEN, Giorgio. Pilatos e Jesus. São Paulo: Boitempo; Florianópolis: Editora da UFSC, 2014. 
BERNADAC, Marie-Laure; HOLLIER, Denis; LA BEAUMELLE, Agnès de (Org.). Leiris \& Co.: Picasso, Masson, Miró, Giacometti, Lam, Bacon... Paris: Gallimard/Centre Pompidou-Metz, 2015.

BENJAMIN, Walter. Obras Escolhidas, vol. I: Magia e técnica, arte e política. São Paulo: Brasiliense, 1987.

FRAZER, James George. The Golden Bough: A Study in Magic and Religion. London: Macmillan Press, 1978.

LEIRIS, Michel. Le sacré dans la vie quotidienne. In: HOLLIER, Denis (Org.). Le Collège de Sociologie. Paris: Gallimard, 1938.

. A Idade Viril. São Paulo: Cosac Naify, 2003.

MORAES, Eliane Robert. O Corpo Impossivel: A decomposição da figura humana de Lautréamont a Bataille. São Paulo: Iluminuras, 2012.

PEREIRA, Edilson. O Teatro da Religião: A Semana Santa em Ouro Preto vista através de seus personagens. Tese de doutorado em Antropologia Social. Rio de Janeiro: PPGAS/Museu Nacional/Universidade Federal do Rio de Janeiro, 2014.

. As mulheres por trás da face de Cristo: apropriaçôes, performances e ambivalências da Verônica. Religiáo \& Sociedade, v. 35, n. 1, p. 193-215. Disponível em: <http://www.scielo.br/scielo.php?script= sci_arttext\&pid=S0100-85872015000100193>.

. O santo, a face e o outro: quando Cristo e Tiradentes se encontram em Ouro Preto. Etnográfica, v. 20, n. 2, 2016. Disponível em: <http:// etnografica.revues.org/4314>.

TAUSSIG, Michael. Mimesis and Alterity: A particular history of the senses. New York; London: Routledge 1993.

Recebido em: 10/12/2016

Aprovado em: 20/02/2017 
